\title{
Biotransformation of soy whey into a novel functional beverage by Cordyceps militaris $\mathrm{SN}-18$
}

\author{
Yiqiang Dai ${ }^{1,2}$, Jianzhong Zhou ${ }^{1,2,3}$, Lixia Wang ${ }^{2}$, Mingsheng Dong ${ }^{2}$ and Xiudong Xia ${ }^{1,3^{*}}$ (D)
}

\begin{abstract}
Soy whey, a liquid nutritional by-product of soybean manufacture, is rich in proteins, oligosaccharides and isoflavones. Soy whey can be used to produce functional beverages, instead of discarding it as a waste. In this study, unfermented soy whey (USW) and Cordyceps militaris SN-18-fermented soy whey (FSW) were investigated and compared for their physicochemical and functional properties by high performance liquid chromatography (HPLC) and DNA damage assay. Results show that C. militaris SN-18 fermentation could increase the contents of essential amino acids, total phenolic and flavonoid and isoflavone aglycones and eliminate the oligosaccharides in soy whey. Furthermore, $C$. militaris SN-18 could significantly enhance the ABTS radical scavenging ability, reducing power and ferric reducing power of soy whey, and its fermented products could prominently attenuate Fenton reaction-induced DNA damage. These findings indicate that soy whey can potentially be converted into a novel soy functional beverage by $C$. militaris SN-18 fermentation.
\end{abstract}

Keywords: Soy whey, Cordyceps militaris, Fermentation, Antioxidant capacity, DNA damage protection

\section{Introduction}

Soy whey, a by-product of soybean production, can be produced in large quantities when tofu is pressed to remove excess moisture. It reported that $8.95 \mathrm{~kg}$ soy whey could be produced when the traditional craft is applied to processing $1 \mathrm{~kg}$ soybean (Tu Tang, Azi Hu \& Dong 2019). Soy whey is characterized by high chemical and biochemical oxygen demand due to a large number of nourishing substances, such as soy protein, fat, isoflavones, saponins, stachyose, and raffinose (Wang \& Serventi 2019).

Soy whey is employed as a potential resource for various purposes. It is used for the recovery of magnesium ions and for the separation of isoflavone aglycones, proteins and oligosaccharides (Chua \& Liu 2019; Liu Zhang Wu

\footnotetext{
* Correspondence: 86084056@163.com

'Institute of Agricultural Product Processing, Jiangsu Academy of Agricultural Sciences, Nanjing 210014, People's Republic of China

${ }^{3}$ School of Food and Biological Engineering, Jiangsu University, 301 Xuefu

Road, Zhenjiang, Jiangsu 212013, People's Republic of China

Full list of author information is available at the end of the article
}

Wang \& Wang 2013). Soy whey also can serve as a liquid fermentation substrate to obtain functional substances, such as $\beta$-galactosidase (Kumari Panesar \& Panesar 2011). However, much waste is generated during the process of target substance extraction and purification, and achieving zero pollution of soy whey is difficult when current extraction methods are applied. Biotransforming soy whey into edible food and beverage products directly can reduce environmental pollution during the manufacture of soybean products, which is an ideal solution to soy whey utilization. Apart from the improvement in taste, microbial fermentation can result in increases in the contents of the secondary physiologically active substances and enhancement in the products' functional properties. Kombucha, Saccharomyces cerevisiae and Lactobacillus plantarum fermentation could lead to the development of soy whey-based beverages that are cheap, nutritious and highly functional (Chua Lu \& Liu 2017; Tu et al. 2019; Xiao et al. 2015). The soy-derived food consumption is somewhat limited by the presence of non-digestible food

(c) The Author(s). 2021 Open Access This article is licensed under a Creative Commons Attribution 4.0 International License, which permits use, sharing, adaptation, distribution and reproduction in any medium or format, as long as you give appropriate credit to the original author(s) and the source, provide a link to the Creative Commons licence, and indicate if changes were made. The images or other third party material in this article are included in the article's Creative Commons licence, unless indicated otherwise in a credit line to the material. If material is not included in the article's Creative Commons licence and your intended use is not permitted by statutory regulation or exceeds the permitted use, you will need to obtain permission directly from the copyright holder. To view a copy of this licence, visit http://creativecommons.org/licenses/by/4.0/. 
ingredients, such as stachyose and raffinose, which can cause intestinal disturbance (Geng et al. 2020). $\alpha$ Galactosidases can be produced directly by microbial fermentation and hydrolyze the $\alpha$-galactosidic linkages of raffinose and stachyose; thus, they effectively eliminate the oligosaccharides in soy products (Xia et al. 2019).

Phenolic compounds have actual and potential effects on human health, such as preventing oxidation, inflammatory reaction, carcinogenesis, and DNA mutations (Wang Luo Wu Liu \& Wu 2018; Xia et al. 2019). Isoflavones, which are considered to be the most bioactive compounds in soybean, can play an important role in scavenging radicals, reducing a person's risk of cancers, and relieving osteoporosis and women's menopausal symptoms (Xia et al. 2019). Isoflavone aglycone could be absorbed directly through the intestinal epithelium without the required residence time to hydrolyze the glycoside moiety. They are known to exhibit marked biological activity than isoflavone glucosides (Hsiao Ho \& Pan 2020). Microbial fermentation was proved to enhance the levels of bioactive phenolic compounds and flavonoids, transform isoflavone glucoside forms into their corresponding aglycone forms, and produce new antioxidants (Chua et al. 2017; Xia et al. 2019).

Cordyceps militaris, an entomogenous fungus, is a wellknown folk tonic food and crude drug used in traditional Chinese medicine. Liquid state fermentation of C. militaris is conducive to mycelial growth and production of exo-biopolymer and has a broad application prospect (Park Kim Hwang \& Yun 2001). During fermentation, proteolytic enzymes produced by $C$. militaris can lead to proteolytic degradation and production of smaller nitrogen compounds (Han Rombouts \& Nout 2004; Xiao et al. 2015). These small compounds including peptides and amino acids can contribute to increasing the nutritious components and enhancing the flavor and aroma of products. Xiao Xing et al. (2015) reported that C. militaris fermentation could enhance the antioxidant activities and the in vitro protein digestibility of chickpea flours.

This study purposed to systematically assess chemical compositions and functional properties of soy whey fermented by $C$. militaris SN-18. Specifically, this work focuses on investigating oligosaccharides, amino acids, isoflavone profiles, antioxidant activities, and the DNA damage protection of USW and FSW.

\section{Materials and methods Materials}

The compounds 2,2-azinobis (3-ethyl benzothiazoline-6sulfonic acid) diammonium salt (ABTS), daidzin, glycitin, genistin, daidzein, glycitein and genistein were obtained from Sigma-Aldrich Chemical Co., Ltd. (St. Louis, MO, USA). HPLC-grade acetonitrile and methanol were from Merck Chemicals Co., Ltd. (Darmstadt, HE, Germany).
Fenton's reagent (FR) contained $3 \mu \mathrm{L}$ of $0.08 \mathrm{mM} \mathrm{FeSO}_{4}$, $4 \mu \mathrm{L}$ of $30 \%(\mathrm{v} / \mathrm{v}) \mathrm{H}_{2} \mathrm{O}_{2}$ and $3 \mu \mathrm{L}$ of distilled water. All other chemicals employed were of analytical grade and purchased from Macklin Inc. (Shanghai, SHH, China).

\section{Fermentation of soy whey}

C. militaris SN-18 was obtained from the Food Microbiology Laboratory, Nanjing Agricultural University. Soy whey obtained from the gypsum tofu-manufacturing process contained $7.1 \mathrm{mg} / \mathrm{mL}$ of protein, $4.1 \mathrm{mg} / \mathrm{mL}$ of ash, $3.5 \mathrm{mg} / \mathrm{mL}$ of crude fat and $85.2 \mathrm{mg} / \mathrm{mL}$ of carbohydrates.

C. militaris $\mathrm{SN}-18$ was placed on potato dextrose agar (PDA) and incubated at $26^{\circ} \mathrm{C}$ for 7 days. The spores were washed three times following centrifugation with sterile distilled water and $5 \%(\mathrm{v} / \mathrm{v})$ of the C. militaris $\mathrm{SN}-18$ spore suspension was inoculated into sterilized soy whey. The fermentation was performed at $26^{\circ} \mathrm{C}$ for 8 days and fermented samples were collected every 2 days during liquid fermentation.

\section{Measurement of $\mathrm{pH}$ value}

The $\mathrm{pH}$ value of soy whey was measured by using a calibrated FiveEasy Plus FP20 pH meter (Mettler-Toledo, Zurich, ZH, Switzerland).

\section{Microbial biomass determination}

The mycelium was harvested by centrifuging at $8000 \mathrm{~g}$ for $20 \mathrm{~min}$ from $100 \mathrm{~mL}$ of soy whey and then the precipitate was washed three times with distilled water. The microbial biomass in soy whey was expressed as grams of wet weight per $100 \mathrm{~mL}$ of FSW.

\section{Reducing sugar and oligosaccharides content determination}

Reducing sugar content was measured by the dinitrosalicylic acid (DNS) method as described by Hu et al. (2008) with modification. Briefly, $1 \mathrm{~mL}$ of FSW and $2 \mathrm{~mL}$ of DNS solution were added into the tube and mixed well. After the tube was placed in a boiling water bath for $5 \mathrm{~min}$, the mixture was transferred into room temperature water bath for $10 \mathrm{~min}$. After $25 \mathrm{~mL}$ of distilled water was added to the tube and mixed well, the absorbance was read at $540 \mathrm{~nm}$. Concentrations were determined by comparing the absorbance of samples with a standard calibration curve constructed by using glucose.

Oligosaccharides content was determined according to the method reported by Wang Yu Yang and Chou (2003). An HPLC system (Waters, Milford, MA, USA) equipped with a refractive index detector was used. $65 \%$ acetonitrile in ultrapure water was used as the mobile phase. After filtered with $0.45 \mu \mathrm{m}$ membrane, $10 \mu \mathrm{L}$ of samples were injected into a Hypersil APS2 column (4.6 $\mathrm{mm} \times 250 \mathrm{~mm}, 5 \mathrm{~mm}$ ) at a flow rate of $2.0 \mathrm{~mL} / \mathrm{min}$. 
Results were expressed as milligram per milliliter of USW or FSW $(\mathrm{mg} / \mathrm{mL})$.

\section{Sensory evaluation}

The FSW underwent sensory evaluation by 15 trained analytical sensory panelists at 2-day intervals. A sensory scoring range of $0-10$ (lowest to highest) was used for organoleptic characteristics and an overall sensory evaluation value was obtained.

\section{Analysis of amino acids and determination of crude protein}

Amino acid composition was determined according to the method reported by Han et al. (2004). After filtered with a $0.45 \mu \mathrm{m}$ membrane, samples were subjected to a HITA CHI L-8900 automatic amino acid analyzer (Hitachi Ltd., Tokyo, Japan) with ninhydrin post-column derivatization and reverse-phase HPLC. Besides, the Kjeldahl method was used to determine the crude protein content.

The determination of tryptophan was carried out on a combined HPLC-ultraviolet system by using the method of Zhu et al. (2010). The samples were centrifuged at $8000 \mathrm{~g}$ for $10 \mathrm{~min}$ and the supernatants were then filtered through $0.45 \mu \mathrm{m}$ membrane for analysis.

\section{Samples solvent extraction}

The soy whey fermented for 6 days and USW were centrifuged at $8000 \mathrm{~g}$ for $10 \mathrm{~min}$ and then the supernatants were lyophilized by FDU-1200 vacuum freeze-drying (EYELA Co., Tokyo, Japan). For water extracts, $1.0 \mathrm{~g}$ of sample mixed with $40 \mathrm{~mL}$ of distilled water and placed on a THZ-C-1 shaking bed (Taichang Scientific Instrument Co., Ltd., China.) at $150 \mathrm{rpm}$ for $3 \mathrm{~h}$ at $40{ }^{\circ} \mathrm{C}$. For ethanol $(80 \%)$ extracts, $1.0 \mathrm{~g}$ of sample was extracted with $40 \mathrm{~mL}$ of ethanol $(80 \%)$ in a water bath at $50{ }^{\circ} \mathrm{C}$ for $4 \mathrm{~h}$. The water and ethanol (80\%) extracts were centrifuged $\left(12,000 \mathrm{~g}\right.$ for $20 \mathrm{~min}$ at $\left.4{ }^{\circ} \mathrm{C}\right)$ and the supernatants were collected. Then, the insoluble residues after centrifugation were re-extracted twice under the same conditions. Thereafter, all the supernatants collected were lyophilized under vacuum and then were dissolved in corresponding extraction solvent to a concentration of $20 \mathrm{mg} / \mathrm{mL}$ for further analysis.

\section{Total phenolic and flavonoid contents determination}

Total phenolic content (TPC) was analyzed through the Foline Ciocalteu (F-C) method described by Xiao et al. (2016). Sample solution $(200 \mu \mathrm{L})$ was added to $2.30 \mathrm{~mL}$ of distilled water, $0.50 \mathrm{~mL}$ of $\mathrm{F}-\mathrm{C}$ reagent and $2.00 \mathrm{~mL}$ of $7.5 \% \mathrm{Na}_{2} \mathrm{CO}_{3}$ solution. The mixture was kept in the dark for $2 \mathrm{~h}$. The absorbance was measured at $700 \mathrm{~nm}$ and the results were expressed as milligram of gallic acid equivalents (GAE)/ g dry extract.
Total flavonoid content (TFC) was performed according to $\mathrm{Tu}$ et al. (2019). Briefly, $250 \mu \mathrm{L}$ of sample solution was mixed with $1.25 \mathrm{~mL}$ of distilled water and $75 \mu \mathrm{L}$ of $5 \%(\mathrm{w} / \mathrm{v}) \mathrm{NaNO}_{2}$, and then the mixtures were kept for 6 min. One hundred fifty microliters of $10 \%(\mathrm{w} / \mathrm{v}) \mathrm{AlCl}_{3}$ was added to incubate for $5 \mathrm{~min}$. Then, $0.5 \mu \mathrm{L}$ of $1 \mathrm{~mol} /$ $\mathrm{L} \mathrm{NaOH}$ and $275 \mu \mathrm{L}$ of distilled water were added into the mixture solution. The absorbance was measured at $510 \mathrm{~nm}$ and the TFC was expressed as milligram of rutin equivalents (RE)/ g dry extract.

\section{Isoflavone content determination}

Isoflavone separation was performed by a HPLC system including a C18 packed column $(4.6 \mathrm{~mm} \times 250 \mathrm{~mm}, 5 \mu \mathrm{m})$ and a PDA-2998 photodiode array detector (Waters, Milford, MA, USA). The isoflavone content was measured as described by Wu et al. (2021).

\section{ABTS radical scavenging ability}

ABTS radical scavenging ability was measured following the method of Xia et al. (2019). The inhibition percentage was calculated according to the equation $\left[1-\left(\mathrm{A}_{\text {sam- }}\right.\right.$ ple $\left.\left./ \mathrm{A}_{\text {control }}\right)\right] \times 100$. The extraction solvent was used as control solvents and Vc was used as a positive control.

\section{Reducing power}

Reducing power was determined by using the method reported by Zhao and Shah (2014) with modification. Sample solution $(0.5 \mathrm{~mL})$ was added to $0.5 \mathrm{~mL}$ of $1 \%(\mathrm{w} / \mathrm{v})$ potassium ferricyanide and $0.5 \mathrm{~mL}$ of $0.2 \mathrm{~mol} / \mathrm{L}$ phosphate buffer (pH 6.6). Before $0.5 \mathrm{~mL}$ of $10 \%$ trichloroacetic acid (TCA) was added to terminate the reaction, the mixture was incubated at $50{ }^{\circ} \mathrm{C}$ for $20 \mathrm{~min}$. The upper layer $(1.5$ $\mathrm{mL}$ ) was collected after centrifugation at $3000 \mathrm{~g}$ for $5 \mathrm{~min}$ and then mixed with $0.2 \mathrm{~mL}$ of $1 \mathrm{mg} / \mathrm{mL} \mathrm{FeCl}_{3}$ for $10 \mathrm{~min}$. Results were expressed as absorbance of the reaction mixture at $700 \mathrm{~nm}$.

\section{Ferric reducing power}

Ferric reducing power was analyzed according to the method previously reported by $\mathrm{Tu}$ et al. (2019). The standard calibration $(100-1600 \mu \mathrm{mol} / \mathrm{L})$ curve was plotted using $\mathrm{FeSO}_{4}$ and the final results were expressed as $\mu \mathrm{mol} / \mathrm{L} \mathrm{FeSO}_{4}$ equivalents.

\section{DNA damage assay}

The prevention of oxidative DNA damage was performed according to Seo et al. (2015). Briefly, $1 \mu \mathrm{L}$ of $0.5 \mu \mathrm{g} / \mathrm{mL}$ plasmid pUC-18 DNA was treated with $10 \mu \mathrm{L}$ of Fenton's reagent and $10 \mu \mathrm{L}$ of extracts at the concentrations of $0.1,0.5,1.0 \mathrm{mg} / \mathrm{mL}$, respectively. After $1 \mathrm{~h}$ of incubation at $37^{\circ} \mathrm{C}, 10 \mu \mathrm{L}$ of reaction mixture along with $6 \times$ DNA loading dye was loaded on a $1 \%$ agarose gel for electrophoresis at $100 \mathrm{~V}$ and photographed with the gel 
documentation system (Bio-Rad Laboratories, Inc., Richmond, CA, USA). The bands were quantified using BioRad Quantity One software program. The untreated pCU-18 plasmid DNA was used as a control and rutin was used as a positive control. The amount of supercoiled DNA was calculated as reported by Xiao, Wang, et al. (2015).

\section{Statistical analysis}

All measurements were carried out in triplicate for each sample and data were expressed as means \pm standard deviation (SD). $\mathrm{EC}_{50}$ values were obtained by interpolation from a linear regression analysis. Analysis of data was performed using one-way ANOVA followed by Duncan's test
(SPSS version 20.0, SPSS Inc., Chicago, IL, USA), and the significance level was set at $P<0.05$.

\section{Results and discussion}

Changes in $\mathrm{pH}$ value and mycelial biomass during fermentation

Figure 1 presents the changes of $\mathrm{pH}$ value and mycelial biomass of $C$. militaris $\mathrm{SN}-18$ in soy whey during fermentation. The initial $\mathrm{pH}$ value of soy whey was approximately 5.83 , which continuously increased to 7.58 after 8 days of fermentation (Fig. 1a). However, in contrast to our result, the $\mathrm{pH}$ value of soy whey fermented by kombucha and lactic acid bacteria showed a continuous decrease due to the continuous production of acetic
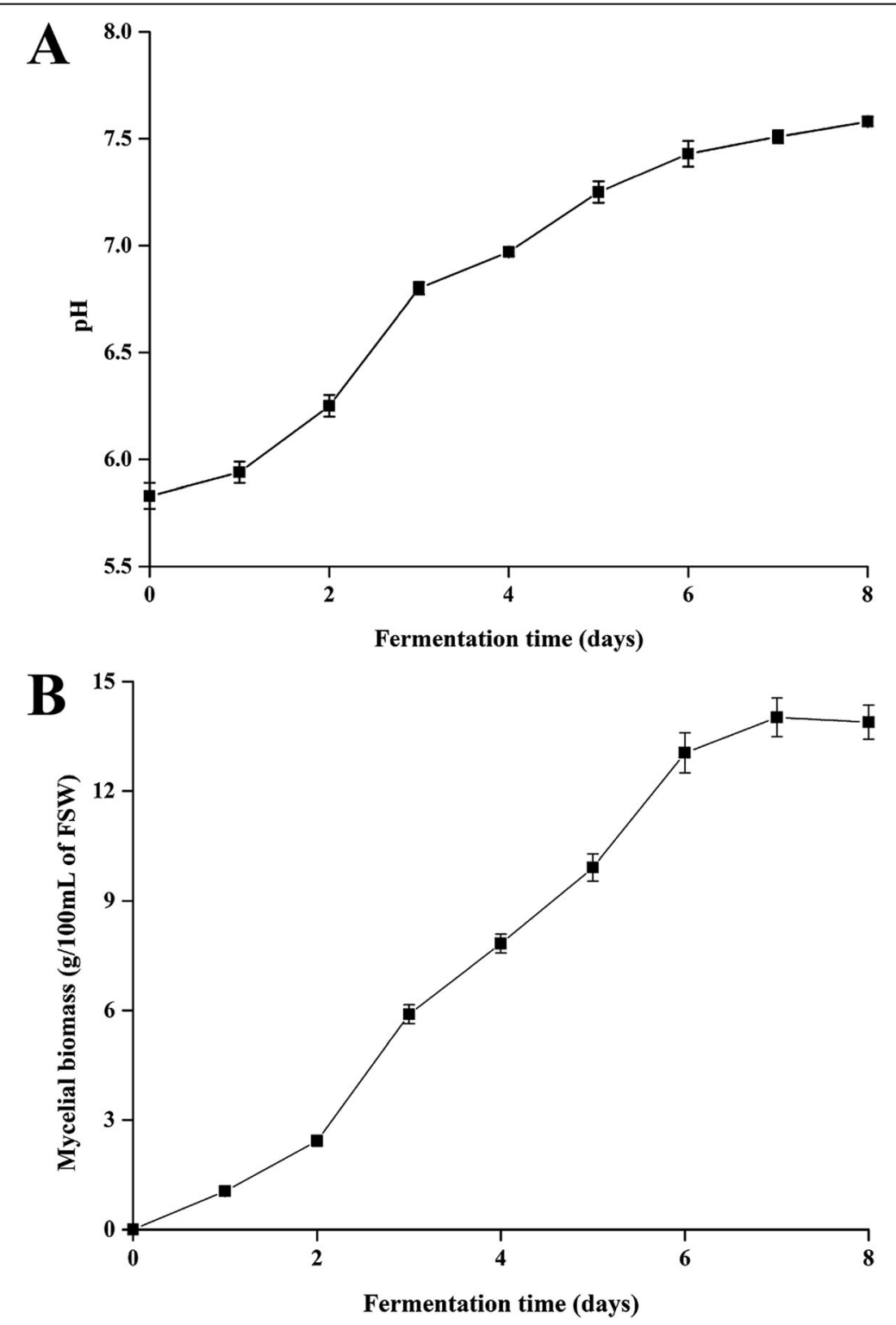

Fig. 1 Physicochemical properties of soy whey fermented with C. militaris SN-18. pH (a) and mycelial biomass (b) 
and lactic acids (Tu et al. 2019; Xiao Wang et al. 2015). C. militaris $\mathrm{SN}-18$ could release ammonia during the fermentation of soy whey (Table 1), which increased the $\mathrm{pH}$ value. The changes in mycelial biomass were in accordance with the changes in $\mathrm{pH}$ value (Fig. 1b). Mycelial biomass in soy whey presented a fast rising trend in the first 6 days, indicating the fast growth of the C. militaris SN-18 in soy whey.

\section{Changes in reducing sugar and oligosaccharides contents during fermentation}

As shown in Fig. 2, the content of reducing sugar in soy whey increased significantly from 0 days to 2 days $(P<0.05)$, which might be attributed to the hydrolysis of macromolecular carbohydrate into reducing sugar. Afterward, the continuous reduction in reducing sugar content was due to the consumption of these reducing sugars by $C$. militaris $\mathrm{SN}-18$.

Sucrose, stachyose, and raffinose can be used as sources of carbon and energy for cell growth (Xia et al. 2019).

Table 1 Total amino acid composition of USW and FSW

\begin{tabular}{|c|c|c|}
\hline & USW & FSW \\
\hline Crude protein & $7.10 \pm 0.07^{\mathrm{a}}$ & $3.66 \pm 0.05^{b}$ \\
\hline $\mathrm{NH}_{3}$ & $2.12 \pm 0.09^{b}$ & $19.07 \pm 0.12^{\mathrm{a}}$ \\
\hline \multicolumn{3}{|l|}{ Non-essential amino acids } \\
\hline Asp & $1.95 \pm 0.08^{b}$ & $3.81 \pm 0.12^{\mathrm{a}}$ \\
\hline Ser & $1.00 \pm 0.05^{b}$ & $3.49 \pm 0.08^{\mathrm{a}}$ \\
\hline Glu & $8.11 \pm 0.23^{b}$ & $16.08 \pm 0.62^{a}$ \\
\hline Gly & $0.91 \pm 0.04^{b}$ & $2.24 \pm 0.07^{a}$ \\
\hline Ala & $2.55 \pm 0.08^{b}$ & $5.56 \pm 0.21^{\mathrm{a}}$ \\
\hline Arg & $14.47 \pm 0.50^{\mathrm{a}}$ & $2.99 \pm 0.04^{b}$ \\
\hline Pro & $1.02 \pm 0.03^{b}$ & $3.00 \pm 0.19^{a}$ \\
\hline Cys & $1.90 \pm 0.04^{\mathrm{a}}$ & $1.24 \pm 0.10^{b}$ \\
\hline Tyr & $1.21 \pm 0.08^{b}$ & $2.21 \pm 0.08^{\mathrm{a}}$ \\
\hline \multicolumn{3}{|l|}{ Essential amino acids } \\
\hline Thr & $0.74 \pm 0.01^{\mathrm{b}}$ & $4.10 \pm 0.09^{\mathrm{a}}$ \\
\hline Val & $1.04 \pm 0.05^{\mathrm{b}}$ & $3.40 \pm 0.08^{\mathrm{a}}$ \\
\hline Met & $0.41 \pm 0.01^{\mathrm{b}}$ & $1.81 \pm 0.10^{\mathrm{a}}$ \\
\hline lle & $0.64 \pm 0.02^{b}$ & $2.46 \pm 0.05^{\mathrm{a}}$ \\
\hline Leu & $0.98 \pm 0.07^{b}$ & $3.82 \pm 0.11^{\mathrm{a}}$ \\
\hline Phe & $1.74 \pm 0.08^{b}$ & $2.51 \pm 0.04^{\mathrm{a}}$ \\
\hline Lys & $1.51 \pm 0.11^{b}$ & $6.01 \pm 0.09^{\mathrm{a}}$ \\
\hline His & $0.94 \pm 0.02^{b}$ & $1.46 \pm 0.01^{\mathrm{a}}$ \\
\hline Trp & $0.06 \pm 0.01^{\mathrm{a}}$ & $0.03 \pm 0.01^{b}$ \\
\hline Total essential amino acids & $8.06 \pm 0.63^{b}$ & $25.60 \pm 0.87^{a}$ \\
\hline Total amino acids & $41.18 \pm 1.22^{\mathrm{b}}$ & $66.22 \pm 1.42^{\mathrm{a}}$ \\
\hline
\end{tabular}

The results were presented as $\mathrm{mg} / \mathrm{mL}$ of soy whey. Data are expressed as mean \pm SD $(n=3)$. Different letters $\left({ }^{\mathrm{a}},{ }^{\mathrm{b}}\right)$ within a row indicate significant difference $(P<0.05)$
These sugars are found in large quantities in soybeans and remain soluble after protein coagulation and migrate to the soy whey (Wang Chen \& Zhang 2014). Figure 2 shows a continuous reduction of sucrose in soy whey during fermentation. The initial contents of raffinose and stachyose were 1.52 and $5.00 \mathrm{mg} / \mathrm{mL}$, respectively. The raffinose and stachyose contents increased to 1.94 and $6.52 \mathrm{mg} / \mathrm{mL}$ during the first day of fermentation, respectively. Afterward, raffinose and stachyose were exhausted within 3 and 5 days of fermentation, respectively. Sucrose was also exhausted within 4 days of fermentation. The hydrolytic enzymes produced by filamentous fungi can depolymerize plant polysaccharides to sugars, which in turn are subsequently used as nutrients for their growth and chemical conversion (Wu Dana Iavarone Clark \& Glass 2017). C. militaris $\mathrm{SN}-18$ possibly broke down the oligosaccharides in soy whey into monosaccharides or disaccharides in the initial stage of fermentation. The sharp depolymerization of oligosaccharides from the second day resulted in increases in reducing sugar content.

Soy whey contains high amounts of stachyose and raffinose, which have many biological activities, such as blood pressure lowering, antidiabetic, immunityenhancing, and liver protection activities; moderate intake of these oligosaccharides can benefit human health (Chen Liu Zhu Xu, \& Li 2010). However, too much intake of these oligosaccharides can cause diarrhea and abdominal distension due to the absence of $\alpha$-galactosidase in the mammalian intestine (Geng et al. 2020). Microbial fermentation is an effective method to reduce stachyose and raffinose contents in soy products because of the action of microorganismderived $\alpha$-galactosidase (Xia et al. 2019). Our results support the conclusion above that C. militaris SN-18 fermentation effectively eliminates raffinose and stachyose in soy whey.

\section{Sensory evaluation}

Combination with taste, flavor, color and overall acceptability, the total sensory score of $C$. militaris-fermented soy whey is shown in Fig. 3. A gradual increase in sensory score was observed during the 6 days of fermentation. However, continuous fermentation caused unpleasant and pungent odor and a large number of hyphae clumps in soy whey. The sensory score decreased on the 7th day of fermentation. In this study, the sixth day after C. militaris $\mathrm{SN}-18$ inoculation served as the end point of the soy whey fermentation.

\section{Amino acids composition}

Table 1 presents the crude protein and amino acid composition of USW and soy whey fermented with $C$. militaris SN-18 for 6 days. C. militaris SN-18 fermentation decreased the protein content in soy whey due 


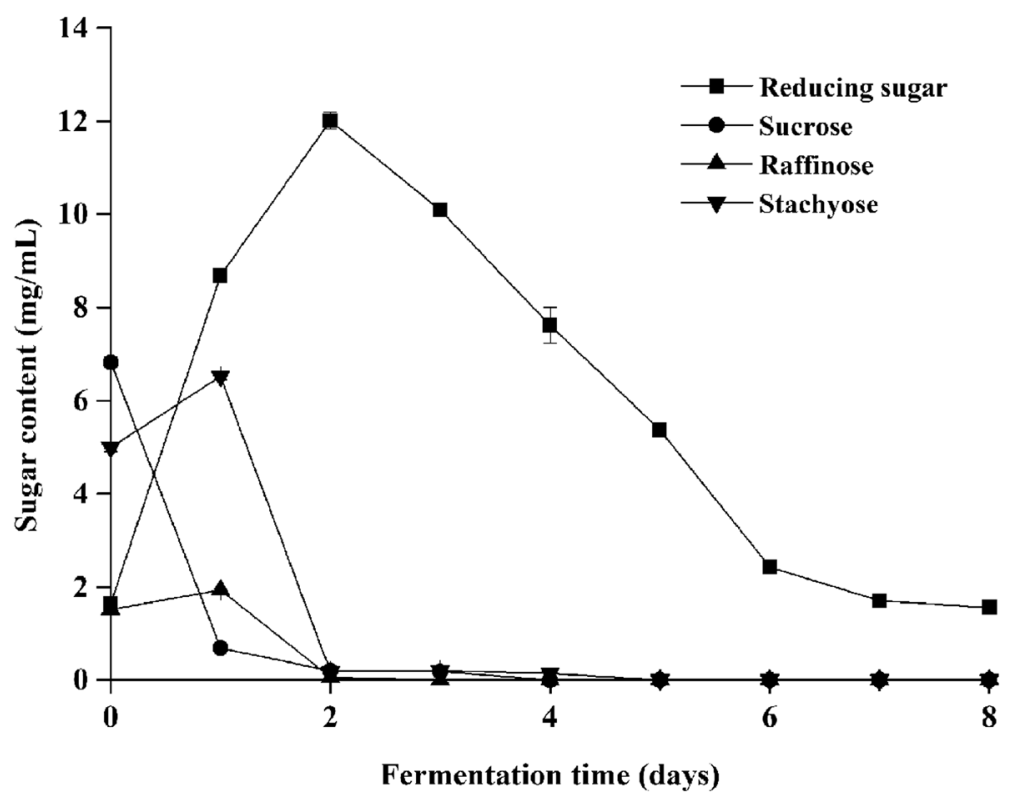

Fig. 2 Contents of reducing sugar and oligosaccharides in soy whey fermented with C. militaris SN-18

to the hydrolysis of proteins to amino acids. The content of all amino acids in FSW increased significantly compared with their original amounts in USW, except for Arg, Cys and Trp (Table 1). Remarkably, compared with USW, the contents of total amino acids and total essential amino acids in FSW increased by 60.81 and $217.62 \%$, respectively. Met, one of the most critical essential amino acids, acts as metabolic factors in cell composition and synthesizes other biochemical compounds for cell metabolism (Kim et al. 2019). Specifically, C. militaris SN-18 fermentation increased the content of Met by $341.46 \%$. Reyes-Bastidas ReyesFernández López-Cervantes Milán-Carrillo and Reyes Moreno (2010) reported that the action of transaminases produced by the fungus could lead to the conversion of amino acids, which in part increased the

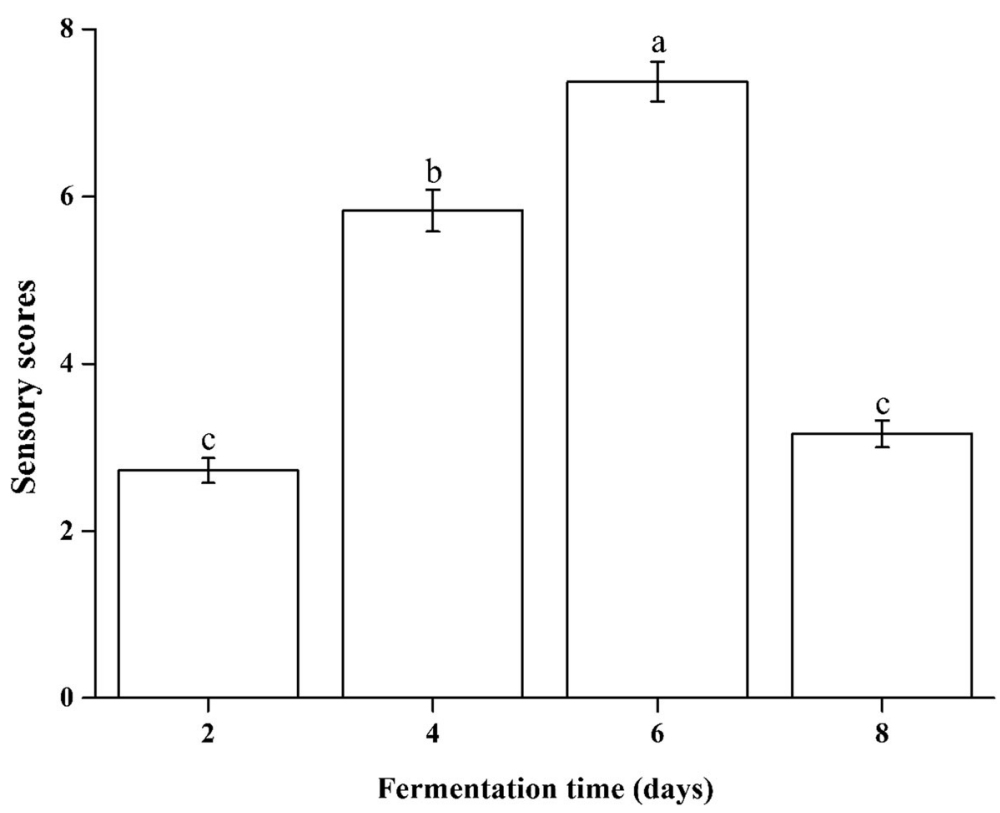

Fig. 3 Sensory evaluation of soy whey fermented with C. militaris SN-18 
amino acid content. Moreover, the increase in total amino acid concentration might be related to the synthesis of these amino acids during fermentation (Xiao Xing et al. 2015).

\section{Changes in TPC, TFC and isoflavone composition in USW and FSW}

Table 2 shows that the TPC and TFC of ethanol (80\%) and water extracts of USW and FSW, respectively. The ethanol (80\%) extracts exhibited higher TPC and TFC than water extracts, and this phenomenon was due to the fact that some phenolic substances were more soluble in organic solvents than in water. Phenolic compounds and flavonoids generally exist in soluble free acids, soluble conjugated and insoluble bound forms (Bei Liu Wang Chen \& Wu 2017). During fermentation, some enzymes derived from microorganisms hydrolyze these phenolic and flavonoid complexes into smaller molecules, thereby increasing the levels of phenolic compounds and flavonoids (Queiroz Santos et al. 2018). The TPC and TFC of FSW were higher than those of USW regardless of the extraction solvent used. In detail, the TPC of FSW in ethanol (80\%) and water extracts increased by 41.67 and $31.27 \%$, respectively, compared with those of USW. The TFC of FSW in ethanol (80\%) and water extract increased by 36.62 and $30.94 \%$, respectively, compared with those of USW. Similar results were obtained by $\mathrm{Tu}$ et al. (2019), who worked with soy whey fermented with kombucha.

$\beta$-glucosidase derived from the secretion of microorganisms can maximally convert the isoflavone glucosides into their corresponding isoflavone aglycones (Wang et al. 2018). Approximately $50 \%$ of isoflavones in soybean are soluble in soy whey during the processing of soybean products (Wang \& Serventi 2019). C. militaris SN-18 fermentation was responsible for the increase of

Table 2 TPC, TFC and isoflavone composition of ethanol (80\%) and water extracts from FSW and USW

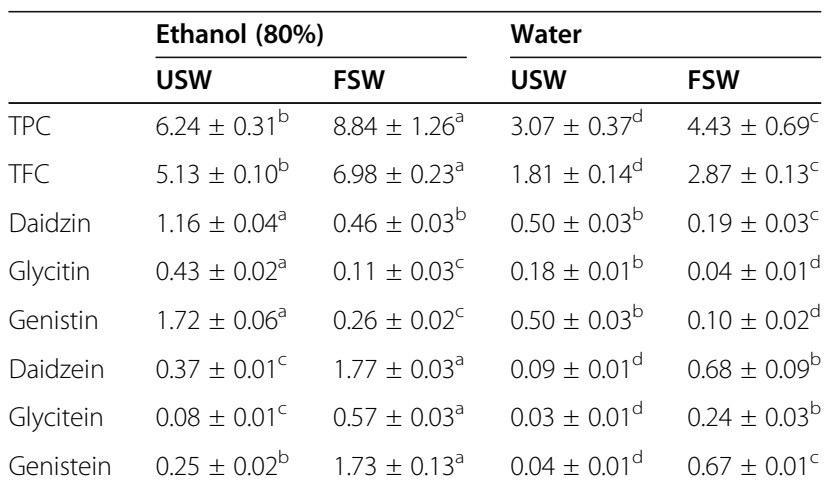

The results of TPC, TFC and isoflavone content were expressed as mg GAE/g dry extract, $\mathrm{mg} R \mathrm{RE} / \mathrm{g}$ dry extract and $\mathrm{mg} / \mathrm{g}$ dry extract, respectively. Data are expressed as mean $\pm \operatorname{SD}(n=3)$. Different letters $\left.{ }^{\left({ }^{-d} d\right.}\right)$ within a row indicate significant difference $(P<0.05)$. isoflavone aglycones content in soy whey. It reported that kombucha and C. militaris could convert the glycone forms to the aglycone forms of isoflavone in soy whey and red beans by producing $\beta$-glucosidase with hydrolytic activity (Tu et al. 2019; Xiao et al. 2016). To further analyze the changes in phenolic composition during fermentation, the main phenolic forms and isoflavone compositions in ethanol $(80 \%)$ or water extracts from USW and FSW were measured (Table 2). The higher isoflavone contents of USW and FSW were obtained in ethanol $(80 \%)$ extracts, indicating that ethanol $(80 \%)$ was more efficient for the extraction of soy isoflavones than water. After $C$. militaris $\mathrm{SN}-18$ fermentation, $60.34-62.00 \%, 74.42-77.78 \%$, and $80.00-84.88 \%$ of daidzin, glycitin, and genistin, respectively, were bioconverted in ethanol (80\%) and water extracts. Therefore, $C$. militaris $\mathrm{SN}-18$ could effectively convert the isoflavone glucosides into their aglycone forms in soy whey during fermentation.

\section{Antioxidant capacity of soy whey fermented with $C$. militaris}

Three antioxidant methods, namely, ABTS radical scavenging activity, reducing power, and ferric reducing power, were used to evaluate the antioxidant effectiveness of the USW and FSW extracts. Figure 4 shows that ABTS radical scavenging activity, reducing power, and ferric reducing power of ethanol (80\%) and water extracts from USW and FSW were all dose-dependent. In addition, these three antioxidant indexes of the ethanol $(80 \%)$ extracts were evidently higher than those of the water extracts, indicating that radical scavenging activity in ethanol (80\%) extracts was higher than that found in water extracts.

As shown in Fig. 4, the ABTS radical scavenging activity, reducing power, and ferric reducing power of FSW were greater than those of USW at the same extraction solvent and extract concentrations. The effectiveness of the antioxidant was inversely correlated with their $\mathrm{EC}_{50}$ values (Xiao Wang et al. 2015). The ABTS scavenging activity of the ethanol (80\%) extracts of FSW (EFSW) had the lowest $\mathrm{EC}_{50}$ value of $0.20 \mathrm{mg} / \mathrm{mL}$, followed by $0.36 \mathrm{mg} / \mathrm{mL}$ for water extracts of FSW (WFSW), $1.07 \mathrm{mg} / \mathrm{mL}$ for ethanol (80\%) extracts of USW (EUSW), and $1.52 \mathrm{mg} / \mathrm{mL}$ for water extracts of USW (WUSW). The $\mathrm{EC}_{50}$ values for ferric reducing power of EFSW, WFSW, EUSW, and WUSW were estimated to be 4.81, 9.25, 9.71, and $11.07 \mathrm{mg} / \mathrm{mL}$, respectively. Therefore, C. militaris SN18 fermentation could enhance the antioxidant capacities of soy whey. These results were consistent with those of Xiao et al. (2016), who found that increases in free radical scavenging activities and 


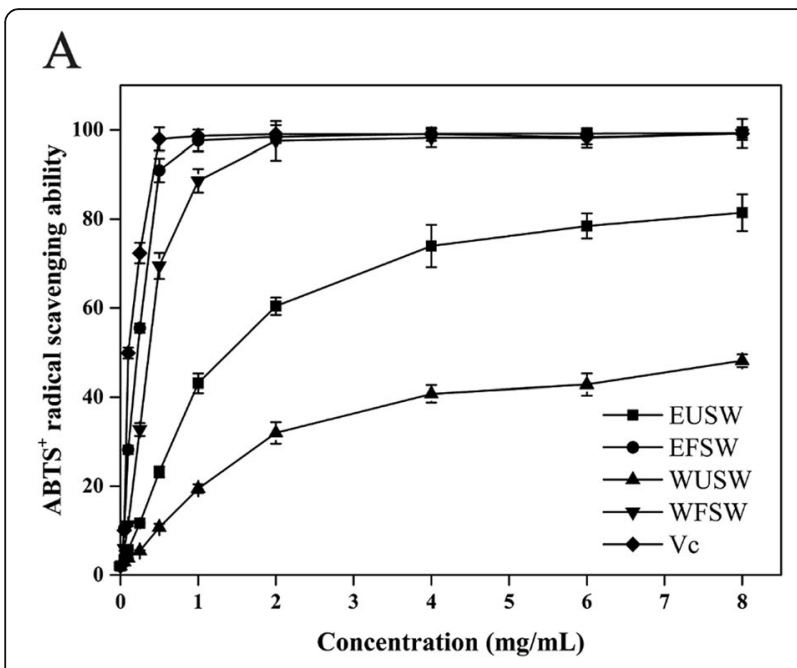

$\mathrm{B}$

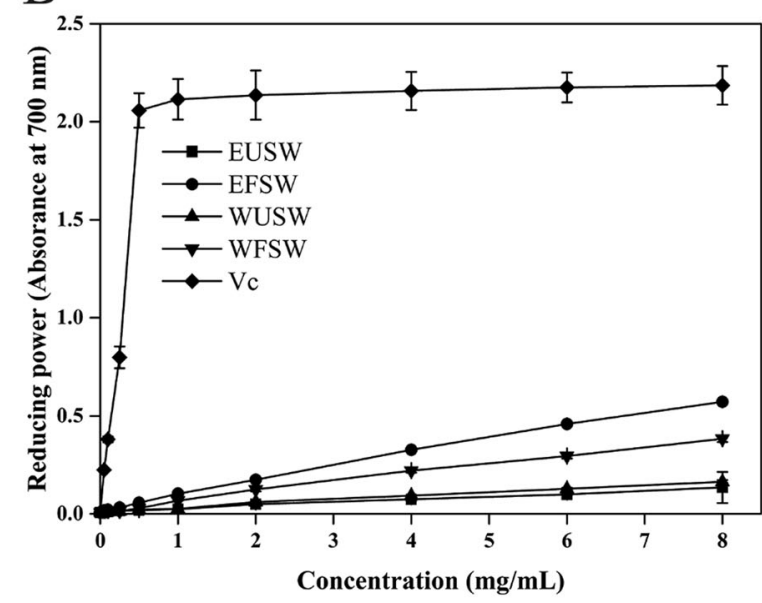

C

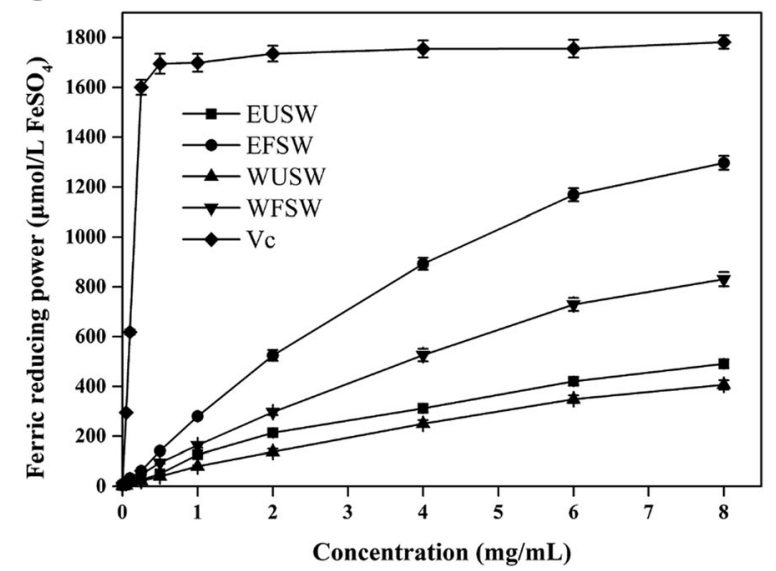

Fig. 4 Antioxidant activities of $80 \%$ ethanol and water extracts from USW and FSW. ABTS radical scavenging activity (a), reducing power (b) and ferric reducing power $(\mathbf{c})$. E- and $\mathbf{W}$ - mean the samples extracted with $80 \%$ ethanol and water, respectively reducing power of red beans were related to $C$. militaris fermentation.

Phenolic compounds and flavonoids can interrupt chain oxidation reactions due to their hydrogen donating capability and metal chelating ability (Li et al. 2020). It has been well demonstrated that the antioxidant activity of products varied significantly and was related to the levels of phenolic substances and flavonoids and to the nature of their chemical structures (Queiroz Santos et al. 2018). The antioxidant potency of isoflavone aglycones is far higher than their corresponding glycoside forms (Xia et al. 2019; Xiao Wang et al. 2015). According to the above mentioned results, FSW had higher antioxidant activities than USW, which may be due to increases in phenolic substances and flavonoids contents and to the bioconversion of isoflavone glycosides into aglycone forms in soy whey.

\section{Protection of cellular DNA from oxidative damage}

Hydroxyl radicals, generated from Fenton reaction in the presence of catalytic transition metals (e.g., $\mathrm{Fe}^{3+}$ ) and $\mathrm{H}_{2} \mathrm{O}_{2}$, can cause the most oxidative damages to biological systems (Seo et al. 2015). They are known to give rise to oxidatively-induced breaks in closed circular supercoiled DNA to yield three forms, namely, supercoiled, open circular, and linear forms (Xiao et al. 2016). In this study, the protective effects of water and ethanol (80\%) extracts of USW and FSW on oxidative DNA damage were investigated.

Compared with the control (lane 2 of Fig. 5a), the supercoiled DNA was completely converted to linear and open circular forms under the treatment of Fenton's reagent (lane 3 of Fig. 5a). However, the addition of USW and FSW extracts into DNA and Fenton's reagent mixture reduced the strand cleavage of supercoiled DNA and retained the supercoiled form. This ability increased with the concentration of USW and FSW. EFSW $(0.5 \mathrm{mg} / \mathrm{mL})$ treatment showed $81.08 \%$ of supercoiled DNA, whereas a significantly lower percentage of supercoiled DNA (61.28\%) was found at the same concentration of WFSW $(P<0.05)$. Moreover, EFSW (WFSW) showed better protection ability for supercoiled DNA than EUSW (WUSW), which corresponded with their antioxidant capacity (Fig. 4). Xiao Wang et al. (2015) reported that $L$. plantarum-fermented soy whey extracts showed $57.91 \%$ of supercoiled DNA, which was higher than that obtained for USW (45.00\%). Singh Singh Singh, and Nautiyal (2010) found that the inhibition of oxidative DNA damage of Trichoderma-fermented soybean extracts was higher than unfermented soybean.

The hydroxyl radical scavenging activity is the main mechanism by which antioxidants inhibit hydroxyl radical-mediated DNA damage (Zhou et al. 2012). 


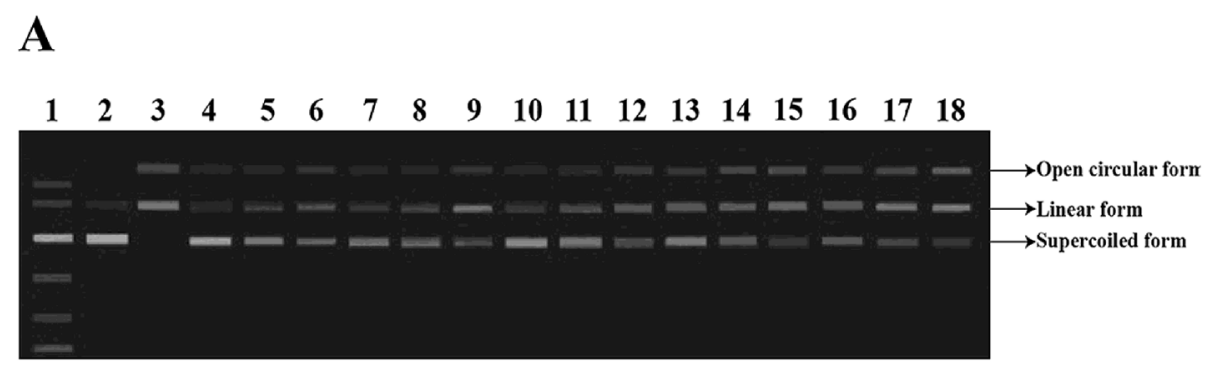

\section{B}

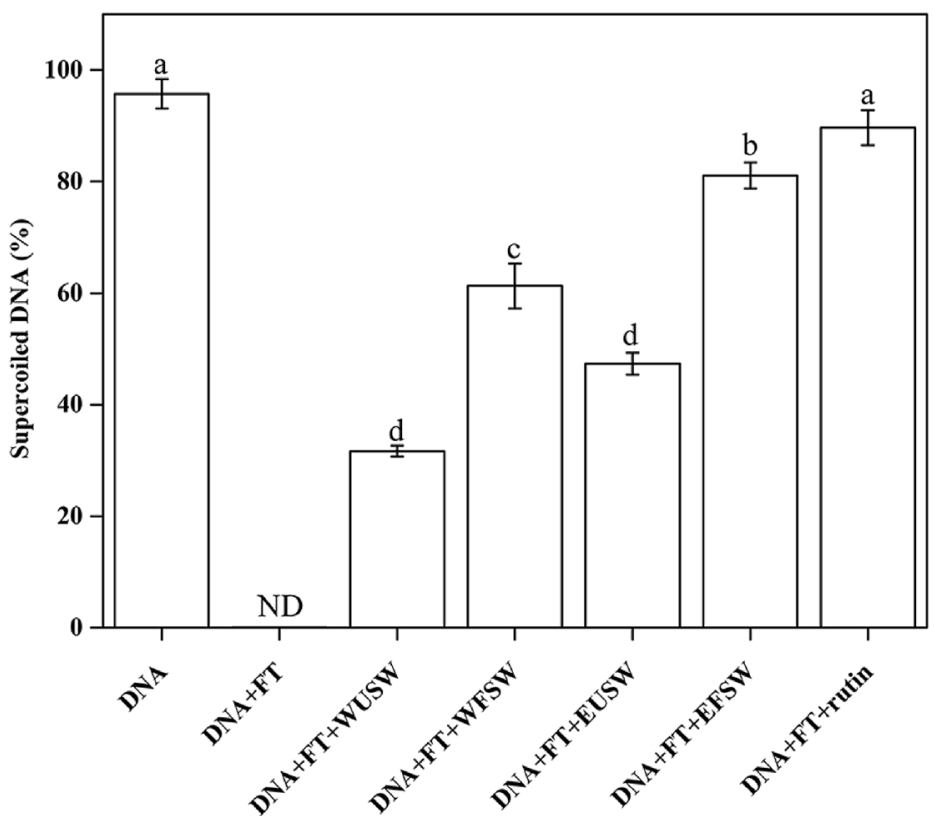

Fig. 5 Protective effect of 80\% ethanol and water extracts from USW and FSW on DNA damage. Lane 1: Marker; lane 2: DNA + PBS; lane 3: DNA + FR; lanes 46: DNA + FR + rutin (1.0, 0.5, $0.1 \mathrm{mg} / \mathrm{mL})$; lanes 7-9: DNA + FR + WFSW (1.0, 0.5, $0.1 \mathrm{mg} / \mathrm{mL}) ;$ lanes 10-12: DNA + FR + EFSW (1.0, 0.5, $0.1 \mathrm{mg} / \mathrm{mL}) ;$ lanes 13-15: DNA + FR + EUSW (1.0, 0.5, $0.1 \mathrm{mg} / \mathrm{mL})$; lanes 16-18: DNA + FR + WUSW (1.0, 0.5, $0.1 \mathrm{mg} / \mathrm{mL})$. E- and W- mean the samples extracted with 80\% ethanol and water, respectively. a Agarose gel electrophoretic patterns of pUC-18 plasmid DNA breaks. $\mathbf{b}$ The content of supercoiled DNA in the presence of $0.5 \mathrm{mg} / \mathrm{mL}$ USW and FSW extracts. Vertical bars represent standard deviations. Means with different lowercase superscripts differ significantly $(P<0.05)$

Polyphenols and flavonoids are considered as the most active antioxidant derivatives which are widely distributed in plants and have ideal structures for the scavenging of free radicals. Marazza Nazareno de Giori and Garro (2012) observed that fermented soymilk was enriched in isoflavone aglycones and its extracts were able to inhibit Fenton reaction-induced oxidative DNA damage. In this study, the enhancement of DNA damage protecting activities of FSW was associated with the increase of phenolic and flavonoid contents. Moreover, isoflavone aglycones are more active as antiradical substances than their corresponding glycoside forms (Marazza et al. 2012). Therefore, the increases of isoflavone aglycones during fermentation can effectively protect plasmid DNA against the strand breakage induced by Fenton reaction. Remarkably, the reducing power, which can contribute to the generation of free hydroxyl radicals during the reduction of $\mathrm{Fe}^{3+}$ to $\mathrm{Fe}^{2+}$, may have a prooxidant effect on DNA (Tian \& Hua 2005). However, in our study, the scavenging hydroxyl radical activity of extracts may predominate over their reducing power on $\mathrm{Fe}^{3+}$, leading to the protective effect on DNA damage.

\section{Conclusion}

Soy whey fermented with C. militaris SN-18 for 6 days presented good acceptability and functional properties. The contents of essential amino acids and total essential amino acids in soy whey were significantly increased and 
the contents of reducing sugar and oligosaccharides were significantly decreased after fermentation. In addition, C. militaris SN-18 fermentation significantly increased the total phenolic, flavonoid and isoflavone aglycones contents of soy whey and enhanced antioxidant capacity and oxidative DNA damage protection ability of soy whey. In conclusion, soy whey can be transformed into a whey-based functional beverage by liquid state fermentation with C. militaris SN-18.

\section{Abbreviations \\ USW: Unfermented soy whey; FSW: Cordyceps militaris SN-18-fermented soy whey; HPLC: High performance liquid chromatography; PDA: Potato dextrose agar; TCA: Trichloroacetic acid; TPC: Total phenolic content; F-C: Foline Ciocalteu; GAE: Gallic acid equivalents; TFC: Total flavonoid content; ABTS: 2,2-azinobis (3-ethyl benzothiazoline-6-sulfonic acid) diammonium salt; EFSW: (80\%) extracts of FSW; WFSW: Water extracts of FSW; EUSW: Ethanol (80\%) extracts of USW; WUSW: Water extracts of USW; FR: Fenton's reagent \\ Acknowledgements \\ Not applicable. \\ Authors' contributions \\ Y. Dai was responsible for the experimental implementation and the manuscript writing. J. Zhou, L. Wang and M. Dong took part in the data analysis and purchase of reagents and materials. X. Xia was responsible for the experimental design, manuscript writing and financial support. All authors reviewed and approved the final version of the manuscript.}

\section{Funding}

The work was supported by the Science and Technology Program of Jiangsu Province (BE2019355), and the National Natural Science Foundation of China (Grant No.31501460).

\section{Availability of data and materials}

All data are available from the corresponding author on reasonable request.

\section{Declarations}

\section{Ethics approval and consent to participate}

Not applicable.

\section{Consent for publication}

All authors consent to the publication of the manuscript.

\section{Competing interests}

There are no conflicts of interest to declare.

\section{Author details}

1 Institute of Agricultural Product Processing, Jiangsu Academy of Agricultural Sciences, Nanjing 210014, People's Republic of China. ${ }^{2}$ College of Food Science and Technology, Nanjing Agricultural University, 1 Weigang Road, Nanjing 210095, People's Republic of China. ${ }^{3}$ School of Food and Biological Engineering, Jiangsu University, 301 Xuefu Road, Zhenjiang, Jiangsu 212013, People's Republic of China.

Received: 20 September 2020 Accepted: 11 February 2021 Published online: 03 April 2021

\section{References}

Bei, Q., Liu, Y., Wang, L., Chen, G., \& Wu, Z. (2017). Improving free, conjugated, and bound phenolic fractions in fermented oats (Avena sativa L.) with Monascus anka and their antioxidant activity. Journal of Functional Foods, 32, 185-194.

Chen, H., Liu, L. J., Zhu, J. J., Xu, B., \& Li, R. (2010). Effect of soybean oligosaccharides on blood lipid, glucose levels and antioxidant enzymes activity in high fat rats. Food Chemistry, 119, 1633-1636.

Chua, J. Y., \& Liu, S. Q. (2019). Soy whey: More than just wastewater from tofu and soy protein isolate industry. Trends in Food Science and Technology, 91, 24-32.
Chua, J. Y., Lu, Y., \& Liu, S. Q. (2017). Biotransformation of soy whey into soy alcoholic beverage by four commercial strains of Saccharomyces cerevisiae. International Journal of Food Microbiology, 262, 14-22.

Geng, X., Yang, D., Zhang, Q., Chang, M., Xu, L., Cheng, Y., ... Meng, J. (2020). Good hydrolysis activity on raffinose family oligosaccharides by a novel agalactosidase from Tremella aurantialba. International Journal of Biological Macromolecules, 150, 1249-1257.

Han, B. Z, Rombouts, F. M., \& Nout, M. J. R. (2004). Amino acid profiles of sufu, a Chinese fermented soybean food. Journal of Food Composition and Analysis, 17, 689-698.

Hsiao, Y. H., Ho, C. T., \& Pan, M. H. (2020). Bioavailability and health benefits of major isoflavone aglycones and their metabolites. Journal of Functional Foods, 74, 104164.

Hu, R., Lin, L., Liu, T., Ouyang, P., He, B., \& Liu, S. (2008). Reducing sugar content in hemicellulose hydrolysate by DNS method: A revisit. Journal of Biobased Materials and Bioenergy, 2, 156-161.

Kim, J., Hahn, K., Yoo, D., Jung, H., Hwang, I., Seong, J., \& Yoon, Y. (2019). Methionine-choline deprivation impairs adult hippocampal neurogenesis in C57BL/6 mice. Journal of Medicinal Food, 22, 344-354.

Kumari, D. S., Panesar, P., \& Panesar, R. (2011). Production of $\beta$-galactosidase using novel yeast isolate from whey. International Journal of Dairy Science, 6, 150-157.

Li, S., Jin, Z., Hu, D., Yang, W., Yan, Y., Nie, X., ... Chen, X. (2020). Effect of solidstate fermentation with Lactobacillus casei on the nutritional value, isoflavones, phenolic acids and antioxidant activity of whole soybean flour. LWT - Food Science and Technology, 125, 109264.

Liu, W., Zhang, H., Wu, Z., Wang, Y., \& Wang, L. (2013). Recovery of isoflavone aglycones from soy whey wastewater using foam fractionation and acidic hydrolysis. Journal of Agricultural and Food Chemistry, 60, 7366-7372.

Marazza, J. A., Nazareno, M. A., de Giori, G. S., \& Garro, M. S. (2012). Enhancement of the antioxidant capacity of soymilk by fermentation with Lactobacillus rhamnosus. Journal of Functional Foods, 4, 594-601.

Park, J. P., Kim, S., Hwang, H. J., \& Yun, J. W. (2001). Optimization of submerged culture conditions for the mycelia growth and exo-biopolymer production by Cordyceps militaris. Letters in Applied Microbiology, 33, 76-81.

Queiroz Santos, V. A., Nascimento, C. G., Schmidt, C. A. P., Mantovani, D., Dekker, R. F. H., \& da Cunha, M. A. A. (2018). Solid-state fermentation of soybean okara: Isoflavones biotransformation, antioxidant activity and enhancement of nutritional quality. LWT - Food Science and Technology, 92, 509-515.

Reyes-Bastidas, M., Reyes-Fernández, E., López-Cervantes, J., Milán-Carrillo, J., \& Reyes Moreno, C. (2010). Physicochemical, nutritional and antioxidant properties of tempeh flour from common bean (Phaseolus vulgaris L.). Food Science and Technology International, 16, 427-434.

Seo, K. H., Lee, J. Y., Debnath, T., Kim, Y. M., Park, J. Y., Kim, Y. O., ... Lim, B. O. (2015). DNA protection and antioxidant potential of chestnut shell extracts. Journal of Food Biochemistry, 40, 20-30.

Singh, H. B., Singh, B. N., Singh, S. P., \& Nautiyal, C. S. (2010). Solid-state cultivation of Trichoderma harzianum NBRl-1055 for modulating natural antioxidants in soybean seed matrix. Bioresource Technology, 101, 64446453.

Tian, B., \& Hua, Y. (2005). Concentration-dependence of prooxidant and antioxidant effects of aloin and aloe-emodin on DNA. Food Chemistry, 91, 413-418.

Tu, C., Tang, S., Azi, F., Hu, W., \& Dong, M. (2019). Use of kombucha consortium to transform soy whey into a novel functional beverage. Journal of Functional Foods, 52, 81-89.

Wang, L., Luo, Y., Wu, Y., Liu, Y., \& Wu, Z. (2018). Fermentation and complex enzyme hydrolysis for improving the total soluble phenolic contents, flavonoid aglycones contents and bio-activities of guava leaves tea. Food Chemistry, 264, 189-198.

Wang, Y., Chen, P., \& Zhang, B. (2014). Quantitative trait loci analysis of soluble sugar contents in soybean. Plant Breeding, 133, 493-498.

Wang, Y., \& Serventi, L. (2019). Sustainability of dairy and soy processing: A review on wastewater recycling. Journal of Cleaner Production, 237, 117821.

Wang, Y. C., Yu, R. C., Yang, H. Y., \& Chou, C. C. (2003). Sugar and acid contents in soymilk fermented with lactic acid bacteria alone or simultaneously with bifidobacteria. Food Microbiology, 20, 333-338.

Wu, H., Dong, J. J., Dai, Y. Q., Liu, X. L., Zhou, J. Z., \& Xia, X. D. (2021). Effects of lactic acid bacteria fermented yellow whey on the protein coagulation and isoflavones distribution in soymilk. Food Chemistry, 334, 127484.

Wu, V., Dana, C., lavarone, A., Clark, D., \& Glass, N. (2017). Identification of glutaminyl cyclase genes involved in pyroglutamate modification of fungal lignocellulolytic enzymes. mBio, 8, e02231-e02216. 
Xia, X., Dai, Y., Wu, H., Liu, X., Wang, Y., Yin, L., ... Zhou, J. (2019). Kombucha fermentation enhances the health-promoting properties of soymilk beverage. Journal of Functional Foods, 62, 103549.

Xiao, Y., Wang, L., Rui, X., Li, W., Chen, X., Jiang, M., \& Dong, M. (2015). Enhancement of the an-tioxidant capacity of soy whey by fermentation with Lactobacillus plantarum B1-6. Journal of Functional Foods, 12, 33-44.

Xiao, Y., Xing, G., Rui, X., Li, W., Chen, X., Jiang, M., \& Dong, M. (2015). Effect of solid-state fermentation with Cordyceps militaris SN-18 on physicochemical and functional properties of chickpea (Cicer arietinum L.) flour. LWT - Food Science and Technology, 63, 1317-1324.

Xiao, Y., Zhang, B., Chen, Y., Miao, J., Zhang, Q., Rui, X., \& Dong, M. (2016). Solidstate bioprocessing with Cordyceps militaris enhanced antioxidant activity and DNA damage protection of red bean (Phaseolus angularis). Cereal Chemistry, 94, 177-184.

Zhao, D., \& Shah, N. P. (2014). Changes in antioxidant capacity, isoflavone profile, phenolic and vitamin contents in soymilk during extended fermentation. LWT - Food Science and Technology, 58, 454-462.

Zhou, J., Li, P., Cheng, N., Gao, H., Wang, B., Wei, Y., \& Wei, C. (2012). Protective effects of buckwheat honey on DNA damage induced by hydroxyl radicals. Food and Chemical Toxicology, 50, 2766-2773.

Zhu, Y., Yang, Y., Zhou, Z., Li, G., Jiang, M., Zhang, C., \& Chen, S. (2010). Direct determination of free tryptophan contents in soy sauces and its application as an index of soy sauce adulteration. Food Chemistry, 118, 159-162.

\section{Publisher's Note}

Springer Nature remains neutral with regard to jurisdictional claims in published maps and institutional affiliations.

Ready to submit your research? Choose BMC and benefit from:

- fast, convenient online submission

- thorough peer review by experienced researchers in your field

- rapid publication on acceptance

- support for research data, including large and complex data types

- gold Open Access which fosters wider collaboration and increased citations

- maximum visibility for your research: over $100 \mathrm{M}$ website views per year

At $\mathrm{BMC}$, research is always in progress.

Learn more biomedcentral.com/submissions 